\title{
Prevalence of Clostridium perfringens toxin genotypes in enterotoxemia suspected sheep flocks of Andhra Pradesh
}

\author{
N. Vinod Kumar, D. Sreenivasulu and Y. N. Reddy \\ Department of Veterinary Microbiology, College of Veterinary Science, Tirupathi, Andhra Pradesh, India. \\ Corresponding author: N. Vinod Kumar, e-mail: nagaram_vinod@yahoo.com, \\ DS: dsreenivasulu10@gmail.com, YNR: drynreddy@rediffmail.com \\ Received: 31-07-2014, Revised: 11-11-2014, Accepted: 19-11-2014, Published online: 26-12-2014
}

doi: 10.14202/vetworld.2014.1132-1136. How to cite this article: Vinod Kumar N, Sreenivasulu D, Reddy YN (2014) Prevalence of clostridium perfringens toxin genotypes in enterotoxemia suspected sheep flocks of Andhra Pradesh, Veterinary World 7(12): 1132-1136.

\begin{abstract}
Aim: To identify the Clostridium perfringens toxin genotypes prevailing in enterotoxemia suspected sheep flocks in Andhra Pradesh by using multiplex PCR.

Materials and Methods: Intestinal scrapings were collected from lambs below three months of age from flocks with similar management from different Districts of Andhra Pradesh, in India. A total of 208 samples were collected with 140 from enterotoxemia suspected flocks and 68 from healthy flocks. Following processing and culture of the samples, colonies were identified by morphological and biochemical tests. All the clostridial isolates were analyzed by multiplex PCR.

Results: C. pefringens were isolated from 97 out of 140 enterotoxemia suspected flocks $(69.29 \%)$ and 27 out of 68 healthy flocks (39.71\%). Genotyping of the 97 iolates by multiplex PCR from enterotoxemia suspected flocks indicated C. perfringens type A, C and D 67.01\% (65 out of 97); 11.34\% (11 out of 97) and 21.65\% (21 out of 97) respectively. Isolates from healthy flocks indicated the presence of type A and D 92.59\% (25 out of 27) and 7.40\% (2 out of 27) respectively. Number of isolates from enterotoxaemia suspected flocks were significantly high $(\mathrm{P}<0.001)$ than healthy flocks. Type $\mathrm{A}$ is found to be predominant in both enterotoxemia suspected and healthy flocks $(67.01 \%$ and $92.59 \%)$.
\end{abstract}

Conclusions: Prevalence of C. perfringens type C was reported for the first time in India. Clostridium perfringens type D and type $\mathrm{C}$ were found to be the major causative types for enterotoxemia.

Keywords: Clostridium perfringes, enterotoxaemia, lamb mortality, multiplex PCR, Toxin typing.

\section{Introduction}

Clostridium perfringens is an important anaerobic spore-forming Gram-positive non-motile rods affecting human and animals. The organism can produce up to 16 different toxins and enzymes in various combinations, including lethal toxins [1]. Enterotoxaemia in sheep is caused by different toxin types of C. perfringens with case fatality rates leading to considerable economic losses to the farmers [2]. Outbreaks of enterotoxaemia are reported regularly every year in India (Unpublished data) during the onset of monsoon season, in spite of regular vaccinations in sheep against $C$. perfringens Type D. Lamb mortality with severe enteritis and sudden deaths in sheep suggestive of Type B and Type C infections were also reported from many places in Andhra Pradesh. However, the existence of $C$. perfringens Type $\mathrm{B}$ and $\mathrm{C}$ has not been recorded in India.

Toxin typing of C. Perfringens is important since particular toxin types are associated with specific enteric diseases in animals [1]. Isolation, culturing and typing C. perfringens by conventional methods such as the mouse neutralization tests are laborious, time consuming, expensive and requires the use of

Copyright: The authors. This article is an open access article licensed under the terms of the Creative Commons Attributin License (http:// creative commons.org/licenses/by/2.0) which permits unrestricted use, distribution and reproduction in any medium, provided the work is properly cited. live animals and monovalent diagnostic sera. Apart from the ethical considerations, the mouse neutralization test, also suffers from a lack of precision and variability of results [3]. Rapid and easy to use in vitro techniques like ELISA are used to demonstrate the toxins in the intestinal contents of diseased animals $[4,5]$ with limited options for subtyping. Failure to demonstrate toxins by an in vivo or in vitro assays cannot completely rule out the $C$. perfringens infection as some strains may not be able to produce toxins in measurable amounts under laboratory conditions [6].

Toxin genotyping is found to be more reliable than the classical toxino typing [7]. Identification of toxin genes rather than the toxins they produce will help to identify the prevailing $C$. perfringens types in a geographical region. It is difficult to classify the isolates into toxigenic types by colony morphology, biochemical properties, analysis of fatty acids and organic acid end products of metabolism by gas-liquid chromatography [2]. Polymerase chain reaction (PCR) typing could demonstrate the presence of the encoding gene(s) in the bacterial genome [3] or in plasmid.

Various reports are available on application of multiplex PCR assays to identify $c p a, c p b$, etx, iap, cpe and cpb2 genes of $C$. perfringens isolates from different species viz., cattle, sheep, goat, swine and 
poultry [8-14]. There is a need to identify the prevailing $C$. perfringens types in the region to understand the epidemiology of enterotoxaemia in sheep, particularly in lambs which helps in improvement of the most appropriate vaccine [6].

The present study is aimed to standardize multiplex PCR for toxinotyping of $C$. perfringens to investigate the prevalence of $C$. perfringens toxino types using multiplex PCR.

\section{Materials and Methods}

C. perfringens Type D reference strain (No. 49) was obtained from Indian Veterinary Research Institute, Izatnagar, India and $C$. perfringes type $\mathrm{C}$ reference strain was obtained from Indian Immunologicals, Hyderabad, India. The cultures obtained in freeze dried form were revived using reinforced clostridial broth. The cultures were then grown on Perfringens agar plates under anaerobic incubation for $48 \mathrm{~h}$ as per the standard protocol.

Clinical samples were collected from the sheep farms with semi-intensive system of rearing showing lamb mortalities in unvaccinated flocks of Kurnool and Chittoor Districts regions in Andhra Pradesh state of India, during the onset on monsoon. Lambs below three months of age with a history of sudden deaths and/or a green pasty diarrhea, staggering, recumbence and convulsions suggestive of enterotoxaemia were selected. The small intestinal loop with specific lesions like hemorrhages, hyperemic intestinal mucosa with slight to marked red fluid contents of the intestine were collected from the dead lambs and transported to the lab on ice. A total of 208 samples collected from 140 enterotoxaemia suspected and 68 healthy lambs were then inoculated into Robertson's cooked meat medium with brain heart infusion broth and incubated at $37^{\circ} \mathrm{C}$ for $24 \mathrm{~h}$ in McIntosh Field's anaerobic jar containing AnaeroHigas pack with indicator ( make). Bacterial cultures appeared were further streaked on to reinforced clostridial agar. The culture plates were then incubated in anaerobic jar with Anaero-Higas pack at $37^{\circ} \mathrm{C}$ for $48 \mathrm{~h}$. Following incubation, the colonies were provisionally identified using growth characters, colony morphology, grams staining and biochemical tests as per the method described by previous authors [15] to identify $C$. perfringens.

Toxin genotyping of isolates was done based on multiplex PCR test. Since, it difficult to classify the isolates into toxigenic types by colony morphology, biochemical properties, analysis of fatty acids and organic acid end products of metabolism by gas-liquid chromatography [2], in the present study C. perfringens isolates obtained were subjected to multiplex PCR test for detection of toxin genes.

The DNA was extracted from C. perfringens reference strains by high salt treatment method described by previous authors [16]. Two to five single colonies of $C$. perfringens isolates were picked up randomly with a sterile loop and suspended into $100 \mu 1$ of sterile diethylpyrocarbonate treated water. After boiling for $20 \mathrm{~min}$ and centrifugation at $15000 \times \mathrm{g}$ for $5 \mathrm{~min}$, a clear supernatant was used as template DNA for PCR test. Oligonucleotide primers specific to alpha, beta and epsilon toxins of $C$. perfringens were adapted from previous workers [8] (Table-1).

The multiplex PCR was performed using a thermocycler (Kyratech, USA) in a total reaction volume of $25 \mu \mathrm{l}$ containing $2.5 \mu \mathrm{l}$ of $\times 10 \mathrm{Taq}$ buffer A; $0.5 \mu 1$ of $10 \mathrm{mM} \mathrm{d}$ NTP mix; $1 \mu \mathrm{l}$ of $25 \mathrm{mM} \mathrm{MgCl}_{2}$; $0.5 \mu 1$ of Taq DNA polymerase $(5 \mathrm{U} / \mu \mathrm{l}) ; 5 \mathrm{pmol}$ each of alpha and epsilon primers and 10 pmol of beta toxin primer and $1 \mu \mathrm{l}$ of template DNA for reference strain and $2.5 \mu \mathrm{l}$ for clinical isolates. Amplification was obtained with 35 cycles following an initial denaturation step at $94^{\circ} \mathrm{C}$ for $3 \mathrm{~min}$. Each cycle involved denaturation at $94^{\circ} \mathrm{C}$ for $1 \mathrm{~min}$, annealing at $53^{\circ} \mathrm{C}$ for $1 \mathrm{~min}$, synthesis at $72^{\circ} \mathrm{C}$ for $1 \mathrm{~min}$. and the final extension step at $72^{\circ} \mathrm{C}$ for $10 \mathrm{~min}$. Following the multiplex PCR, $10 \mu 1$ of amplified products was separated using electrophoresis in a $1.5 \%$ agarose gel and stained with ethidium bromide. The amplified bands were visualized and photographed under UV illumination.

Sequencing amplified PCR products of alpha, beta and epsilon toxin partial gene segments of $C$. perfringens reference strains and field isolates were purified by using the QIA quick gel extraction kit and purified DNA was sequenced using the ABI 377 Perkin Elmer automated DNA sequencer at sequencing facility, MWG Biotech Pvt. Ltd, Bangalore. Sequence data were analyzed using BLAST N software (http://www.ncbi.nlh.nih.gov/BLAST/cgi) with non-redundant database.

All the isolates $C$. perfringens obtained from healthy and enterotoxemia suspected flocks in this study were screened by multiplex PCR and the result were tabulated. The prevalence of $C$. perfringens in different groups was compared using the Chi-square test.

Table-1: Primers used for multiplex PCR in the preset study.

\begin{tabular}{|c|c|c|c|c|}
\hline Toxin Gene & Primers & Primer position & $(G+C) \%$ & Product size \\
\hline Alpha Cpa & $\begin{array}{l}\text { F- 5'-GCT AAT GTT ACT GCC GTT GT-3' } \\
\text { R- 5'-CCT CTG ATA CAT CGT GTA AG-3' }\end{array}$ & $\begin{array}{l}1438-1457 \\
1762-1743\end{array}$ & $\begin{array}{l}45 \\
40\end{array}$ & 324 bp \\
\hline Beta $C p b$ & $\begin{array}{l}\text { F- 5'-GCG AAT ATG CTG AAT CAT CTA-3' } \\
\text { R- 5'-GCA GGA ACA TTA GTA TAT CTT C-3' }\end{array}$ & $\begin{array}{c}871-891 \\
1067-1046\end{array}$ & $\begin{array}{l}38 \\
36\end{array}$ & 196 bp \\
\hline Epsilon Etx & $\begin{array}{l}\text { F- 5'-GCG GTG ATA TCC ATC TAT TC-3' } \\
\text { R- 5'-CCA CTT ACT TGT CCT ACT AAC-3' }\end{array}$ & $\begin{array}{l}227-246 \\
882-862\end{array}$ & $\begin{array}{l}45 \\
42\end{array}$ & 655 bp \\
\hline
\end{tabular}




\section{Results and Discussion}

Results of multiplex PCR test for detection of toxin genes of $C$. perfringens revealed simultaneous amplification of alpha (cpa $324 \mathrm{bp}$ ), beta (cpb $196 \mathrm{bp}$ ) and epsilon (etx $655 \mathrm{bp}$ ) toxin genes in various combinations indicating the presence of $C$. perfringens toxin types A, C and D, respectively (Figure-1). However, none of the isolates showed simultaneous amplification of all the three genes of alpha, beta and epsilon toxins in multiplex PCR test, indicating the absence of C. perfringens toxin Type B among the isolates.

Out of 208 samples attempted for isolation from enterotoxaemia suspected and healthy lambs, $124(59.62 \%)$ isolates of $C$. perfringens were obtained. Out of which, 97 (69.29\%) were obtained from a total of 140 samples collected from enterotoxaemia suspected lambs, whereas $27(39.71 \%)$ isolates were obtained from a total of 68 samples collected from healthy slaughter animals. The results showed a significant difference $(p<0.001)$ between enterotoxaemia suspected and healthy groups in terms of number of isolates of $C$. perfringens (Table-2).

All 124 isolates of $C$. perfringens were subjected to multiplex PCR for confirmation of toxin type. The results of toxin typing was presented in (Table-3).

BLAST analysis of purified PCR products was found to be showing $100 \%$ homology with corresponding published toxin genes confirming the amplicons as alpha (321 bp), beta (196 bp) and epsilon (655 bp) genes of $C$. perfringens. Two alpha and three epsilon toxin genes partial sequences were published with
Gen bank accession numbers JX091649; JX074046 and JX033910; JX035899; JX112705 respectively.

Though $C$. perfringens was considered as part of normal intestinal flora [17] the significant increase in the number between enterotoxaemia suspected and healthy samples in the present study has diagnostic significance. Toxin typing of isolates revealed an increase in a number of $C$. perfringens Type A and D in cases of enterotoxaemia in lambs, though $C$. perfringens is the normal gut inhabitant of sheep [18].

All the 124 isolates were tested by multiplex PCR for identification of toxin types. Among the total isolates Type A was found to be the predominant toxin type $(72.58 \%)$ followed by Type D $(18.55 \%)$ and Type C $(8.87 \%)$. The results of the higher proportion of type A are in concurrence with the earlier reports of toxin typing of $C$. perfringens isolates by multiplex PCR test from enterotoxaemia suspected, and healthy sheep flocks $[5,6,19]$. Toxin Type A isolates were often physiologically similar to other toxin types [20]. The only difference between toxin Types A and D is the epsilon toxin [2], which is plasmid-borne and the gene could be acquired horizontally [7].

Type B was reported as most prevalent toxin type representing $46.00 \%$ of cases of clostridial dysentery, followed by Type D in $28.00 \%$, Type C in $20.00 \%$ of cases [21]. Two Type D (7.40\%) were found out of 27 apparently healthy animal samples in the present study. Presence of Type D in apparently healthy animal samples were also demonstrated by previous

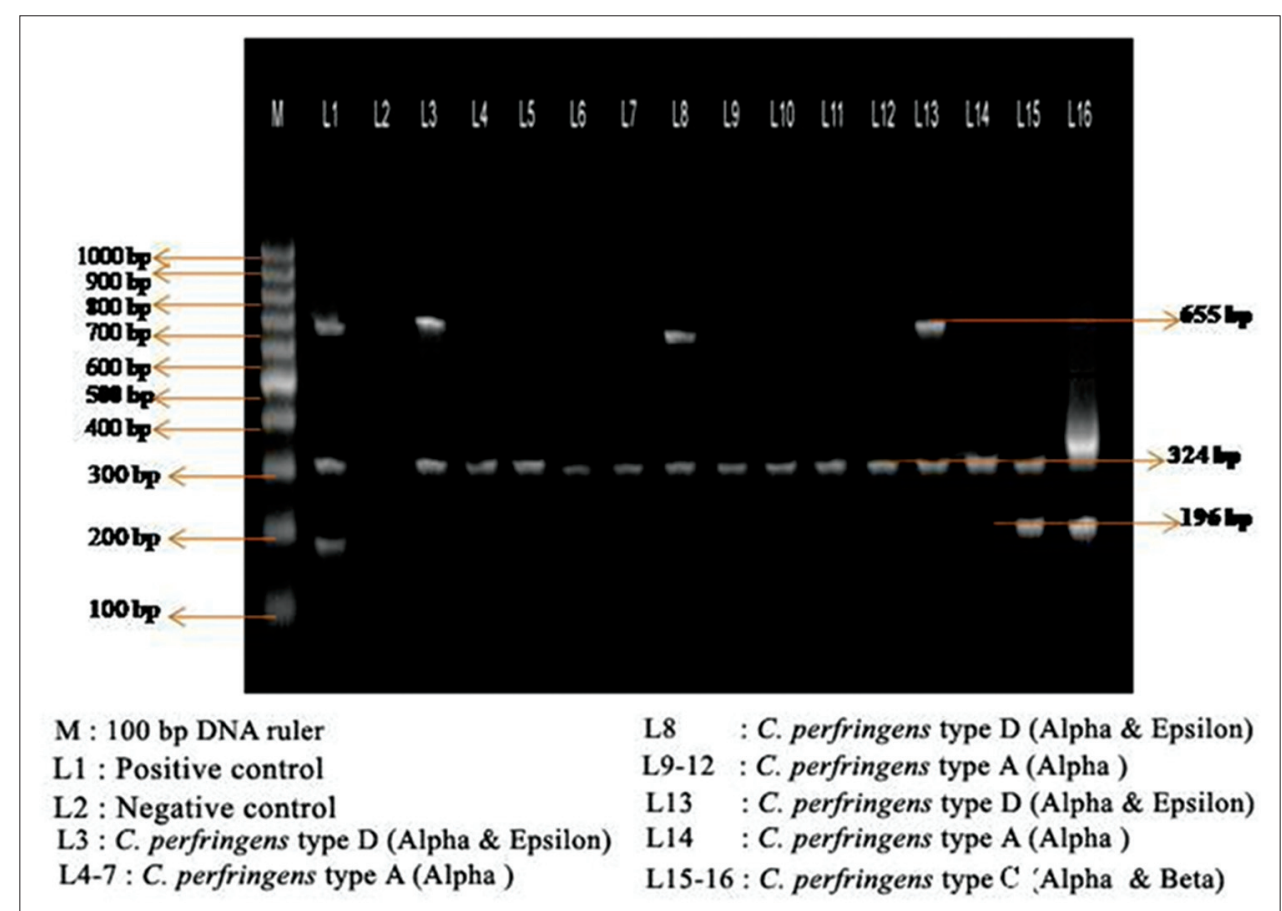

Figure-1: Agarose gel electrophoresis of amplicons of alpha, beta and epsilon toxin genes of Clostridium perfringens isolates screened by multiplex Polymerase chain reaction, M: 100 bp DNA ruler, L1: Positive control, L2: Negative control, L3: Clostridium perfringens Type D (Alpha and Epsilon), L4-7: Clostridium perfringens Type A (Alpha), L8: Clostridium perfringens Type D (Alpha and Epsilon), L9-12: Clostridium perfringens Type A (Alpha), L13: Clostridium perfringens Type D, L14: Clostridium perfringens Type A, L15-16: Clostridium perfringens Type C. 
Table-2: C. perfringens isolates obtained from in enterotoxaemia suspected and healthy groups of samples.

\begin{tabular}{lccc}
\hline \multirow{2}{*}{$\begin{array}{l}\text { Type of } \\
\text { samples } \\
\text { collected }\end{array}$} & $\begin{array}{c}\text { No. of } \\
\text { samples } \\
\text { screened }\end{array}$ & \multicolumn{2}{c}{$\begin{array}{c}\text { Results of C. perfringens } \\
\text { isolation }\end{array}$} \\
\cline { 3 - 4 } & & No. Positives & No. Negatives \\
\hline ET suspected & 140 & $97^{\mathrm{a}}(69.29)$ & $43(30.71)$ \\
Healthy & 68 & $27^{\mathrm{b}}(39.71)$ & $41(60.29)$ \\
Total & 208 & $124(59.62)$ & $84(40.38)$ \\
\hline $\begin{array}{l}* * * p<0.001) \\
\text { perfringens }\end{array}$ & $\mathrm{b} / \mathrm{n}$ a and b, C. perfringens=Clostridium
\end{tabular}

Table 3: Toxin genotyping of $C$. perfringens isolates by multiplex PCR.

\begin{tabular}{lcccc}
\hline $\begin{array}{l}\text { Toxin } \\
\text { geneamplified }\end{array}$ & $\begin{array}{c}\text { Toxin } \\
\text { type }\end{array}$ & $\begin{array}{c}\text { ET } \\
\text { suspected } \\
(\%)\end{array}$ & $\begin{array}{c}\text { Healthy } \\
\mathbf{( \% )}\end{array}$ & $\begin{array}{c}\text { Total } \\
\mathbf{( \% )}\end{array}$ \\
\hline Cpa & \multicolumn{1}{c}{ Type A $65(67.01)$} & $25(92.59)$ & $90(72.58)$ \\
Cpa and $c p b$ & Type C $11(11.34)$ & $0(0)$ & $11(8.87)$ \\
Cpa and etx & Type D $21(21.65)$ & $2(7.40)$ & $23(18.55)$ \\
& Total & 97 & 27 & 124 \\
\hline
\end{tabular}

C. perfringens $=$ Clostridium perfringens, $\mathrm{PCR}=$ Polymerase chain reaction

authors [10]. It was suggested that these animals might be either at an early stage of $C$. perfringens Type $\mathrm{D}$ infections or indicated past infection or carrier status of $C$. perfringens Type D. Large genetic diversity in C. perfringens strains might be because of acquisition or loss of plasmids carrying toxin genes [22].

Isolation of a large number of $C$. perfringens Type $\mathrm{B}$ or $\mathrm{C}$ in pure culture has excellent diagnostic value in the presence of appropriate clinical signs and lesions [23]. C. perfringens beta toxin is considered the main virulent factor in Type C infections [1], which is very sensitive to trypsin digestion. Animals with low levels of intestinal trypsin (lambs) are usually the most susceptible groups for beta toxin producing C. perfringens isolates [1]. Similar conclusions could be made from the present investigation based on Increase in the prevalence of $C$. perfringens Type $\mathrm{D}$ $21(21.65 \%)$ and C $11(11.34 \%)$ in lambs with typical symptoms and lesions of enterotoxaemia, when compared to their negligible presence in healthy animals (3.7\% Type D and $0 \%$ Type C).

In the present trial, $C$. perfringens field isolates were not random and therefore, may not accurately represent the distribution of toxin types in animals or disease conditions. However, the predominance of epsilon toxin-producing isolates and identification of beta toxin in enterotoxaemia suspected flocks for the first time in the region suggests the importance of this toxin types in Clostridial animal diseases in India. Further studies are required to detect other prevailing toxin types of $C$. perfringens in the region.

\section{Conclusion}

The multiplex PCR test is a useful assay for genotyping of $C$. perfringens and is a possible alternative to single gene assay and in vivo typing methods.
In turn, this would simplify the development of specific vaccines using available toxin types suitable to the region. Type $\mathrm{A}$ is found to be predominant in both enterotoxemia suspected and healthy flocks. A higher proportion of $C$. perfringens Type $\mathrm{D}$ and Type $\mathrm{C}$ were associated with sheep suspected of enterotoxemia. Prevalence of $C$. perfringens type $\mathrm{C}$ was reported for the first time in India. Identification of the prevailing toxin types of $C$. perfringens in the region by multiple toxin types will help in production of the polyvalent vaccine to control the diseases.

\section{Authors' Contributions}

NVK planned, designed and carried out research work under his $\mathrm{Ph}$. D thesis programme in collaboration with guide DS and advisory member YNR. DS revised the manuscript. All authors read and approved the final manuscript.

\section{Acknowledgments}

The authors are thankful to Sri Venkateswara Veterinary University, Tirupati, AP, India for providing funding for conducting the Ph.D. Research. The study is a part of the post-graduate research work, "Molecular Characterization of Clostridium perfringens toxin types isolated from sheep of Andhra Pradesh" and submitted by the first author to SVVU, Tirupathi.

\section{Competing of Interests}

The author declare that they have no competing interests.

\section{References}

1. Uzal, F.A., Vidal, J.E., McClane, B.A. and Guraj, A.A. (2014) Clostridium perfringens toxins involved in mammalian veterinary diseases. Open Toxicol. J., 2: 24-42.

2. Rood, J.I. and Cole, S.T. (1991) Molecular genetics and pathogenesis of Clostridium perfringes. Microbiol. Rev., 55(4): 621-648.

3. Carter, G.R. (1984) Diagnostic Procedure in Veterinary Microbiology. Charles C Thomas, Springfield, Illinois.

4. Naylor, R.D. and Barker, L.T. (1997) Detection of Clostridium perfringens alpha toxin by enzyme-linked immunosorbent assay. Res. Vet. Sci., 63(1): 101-102.

5. Greco, G., Madio, A., Buonavoglia, D., Totaro, M., Corrente, M., Martella, V. and Buonavoglia, C. (2005) Clostridium perfringens toxin-types in lambs and kids affected with gastroenteric pathologies in Italy. Vet. J., 170(3): 346-350.

6. Kalender, H., Ertas, H.B., Cetinkaya, B., Muz, A., Arslan, N. and Kilic, A. (2005) Typing of isolates of Clostridium perfringens from healthy and diseased sheep by multiplex PCR. Vet. Med. Czech., 50(10): 141-148.

7. Petit, L., Gibert, M. and Popoff, M.R. (1999) Clostridium perfringens: Toxinotype and genotype. Trend Microbiol., 7(3): 104-110.

8. Songer, J.G. and Meer, R.R. (1996) Genotyping of Clostridium perfringens by polymerase chain reaction is a useful adjunct to diagnosis of clostridial enteric disease in animals. Anae. 2: 197-203.

9. Van Asten, A.J.A.M., Wiel, C.W., Van Nikolaou, G., Houvers, D.J. and Grone, A. (2009) A multiplex PCR for toxin typing of Clostridium perfringens. Vet. Microbiol., 136(3-4): 411-412.

10. Baums, C.G., Schotte, U., Amtsberg, G. and Goethe, R. 
(2004) Diagnostic multiplex PCR for toxin genotyping of Clostridium perfringens isolates. Vet. Microbiol., 100(1-2): 11-16.

11. Josephine, W., Zang, W., Xie, B., Wu, M., Tong, X., Kalpoe, J. and Zhang, D. (2009) Detection and toxin typing of $C$. perfringens in formalin-fixed, paraffin-embedded tissue samples by PCR. J. Clin. Microbiol., 47(3): 807-810.

12. Bedagliacca, P., Provvido, A.D., Scattolini, S., Pompei, G. and Giannatale, E.D. (2010) Toxin genotyping of Clostridium perfringens strains using a polymerase chain reaction protocol. Vet. Ital. 46(1): 113-8, 107-12.

13. Ahsani M R, bafti M S, Esmailizadeh A K and Mohammadabadi M R (2011) Genotyping of isolates of Clostridium perfringens from vaccinated and unvaccinated sheep. Small Ruminant Research 95: 65-69.

14. Gurumu, E.B., Hazarika, R.A., Borah, P. and Barua, A.G. (2013) Presence of enterotoxegenic Clostridium perfringens in food of animal origin, Gowahati, India. J. Environ. Occup. Sci., 2(1): 45-50.

15. Ahsani, M.R., bafti, M.S., Esmailizadeh, A.K. and Mohammadabadi, M.R. (2010) Genotyping of isolates of Clostridium perfringens from vaccinated and unvaccinated sheep. Small. Rumin Res., 95: 65-69.

16. Ramadoss, P. (2006) DNA isolation from bacteriological culture using high salt method, ICAR workshop on emerging biotechnological methods on disease diagnosis.
Department of Animal Biotehonology, MVC, Chennai, $19^{\text {th }}$ April to $9^{\text {th }}$ May, 2006.

17. Cato, E.P., George, W.L. and Finegold, S.M. (1986) Genus clostridium prazmowski 1880, 23 AL. In: Sneath, P.H.A., Mair, N.S., Sharpe, M.E. and Holt, J.G., editors. Bergey's Manual of Systematic Bacteriology. Vol. 1. The Williams \& Wilkins Co., Baltimore. p1141-1200.

18. Popoff, M.R. (1984) Bacteriological examination in enterotoxaemia of sheep and lamb. Vet. Rec., 114(13): 324.

19. Hadimli, H.H., Ergamis, O., Sayin, Z. and Aras, Z. (2012) Toxinotyping of Clostridium perfringens isolates by ELISA and PCR from lambs suspected of enterotoxemia. Turk. $J$. Anim. Sci., 36(4): 409-415.

20. Sawires, Y.S. and Songer, J.G. (1995) Multiple-locus variable-number tandem repeat analysis for strain typing of Clostridium perfringens. Anaerobe, 11(5): 262-272.

21. Gkiourtzidis, K., Frey, J., Bourtzi-Hatzopoulou, E., Iliadis, N. and Sarris, K. (2001) PCR detection and prevalence of alpha-, beta-, beta 2-, epsilon-, iota- and enterotoxin genes in Clostridium perfringens isolated from lambs with Clostridial dysentery. Vet. Microbiol., 82(1): 39-43.

22. Popoff, M.R. (2011) Epsilon toxin is fascinating pore forming toxin. FEBS J., 278(23): 4602-4615.

23. Uzal, F.A. and Songer, G. (2008) Diagnosis of Clostridium perfringens intestinal infections in sheep and goats. J. Vet. Diagn. Invest., 20(3): 253-265. 